\title{
EVALUATION OF PROTONATION CONSTANTS OF MERCAPTOSUCCINIC ACID IN AQUEOUS SOLUTIONS OF PROPYLENE GLYCOL AND DIOXAN
}

\author{
MEKONEN TIRFU ZEKARIAS and GOLLAPALLI NAGESWARA RAO*
}

School of Chemistry, Andhra University, Visakhapatnam-530003, India

(Received: September 14, 2011 - Accepted: December 12, 2011)

\begin{abstract}
The protonation constants values of mercaptosuccinic acid were determined in propylene glycol- and dioxan-water mixtures $(0-60 \% \mathrm{v} / \mathrm{v})$ at $303.0 \mathrm{~K}$ at an ionic strength of $0.16 \mathrm{M}$ using $\mathrm{pH}$-metric technique. The protonation constants were calculated with the computer program MINIQUAD75 and selection of the best fit chemical models was based on the statistical parameters. The log $\mathrm{K}$ values were found to increase with increase of the organic solvent content. The linear variations of the protonation constants with the reciprocal of the dielectric constant of the medium have been attributed to the dominance of electrostatic forces. Distribution of species, protonation equilibria and effect of influential parameters on the protonation constants have also been presented.
\end{abstract}

Keywords: Mercaptosuccinic acid, propylene glycol, dioxan, protonation constant, dielectric constant.

\section{INTRODUCTION}

Mercaptosuccinic acid (MSA) or thiomalic acid (HOOC-CH(SH)- $\mathrm{CH}_{2}-$ $\mathrm{COOH})$ is a dicarboxylic acid containing a thiol functional group (-SH group) instead of an -OH group in malic acid. ${ }^{1}$ It is an important organic compound with multifunctional intermediate in organic synthesis. It is widely used in the synthesis of various biologically active sulfur containing compounds such as the antileukemic spiro[indoline-3,2'-thiazolidine]-2,4'-diones, ${ }^{2}$ and the antimicrobial ${ }^{3,4}$ and antitubercular 4-thiazolidinones. It is also used as a building block in the synthesis of novel polyanionic inhibitors of human immunodeficiency virus and other viruses, ${ }^{5}$ and as a starting material in the synthesis of isocysteine, an important non-proteinogenic amino acid in a potent peptide inhibitor of stromelysin. ${ }^{6}$ In addition, sodium salt of the anionic $\mathrm{Au}(\mathrm{I})$ complex of 2-mercaptosuccinic acid is an effective antiarthritic drug. ${ }^{7-10}$ MSA is widely applied in industry and technology as corrosion inhibitor, electrolyte for electroplating bath, and components of bleach-fixing baths for photographic films and as active materials for depilatories and hair straightening. ${ }^{11}$

MSA is a tridentate ligand which has the ability to form strong complexes with many metal ions in natural environment and within cells ${ }^{12}$ and it has three replaceable hydrogen ions (two from the carboxylic and one from the sulfhydryl functional groups). The determination of protonation constants of MSA is important in understanding its physico-chemical behavior and its interaction with metals under low dielectric constants in organic solvent-water mixtures because it is known that such mixed solvents produce a solvent with quite different properties, both, physically (dielectric, density and viscosity) and chemically (acid-base and donor-acceptor properties) and provide a better model for in vivo reactions. ${ }^{13,14}$

In this paper, the protonation constants of mercaptosuccinic acid have been determined $\mathrm{pH}$-metrically in aqueous solutions containing propylene glycol (PG) and dioxan (DOX), which are binary mixtures used as a solvent frequently in pharmaceutical industry and biochemistry.

\section{EXPERIMENTAL}

\subsection{Chemicals and Standard Solutions}

All the chemicals used in this investigation were of Analytical Reagent grade purity. Triple-distilled deionized water was used for the preparation of all the solutions. 0.05 M Solution of mercaptosuccinic acid (Acros Organic, USA) was prepared by maintaining $0.05 \mathrm{M}$ nitric acid concentration to increase the solubility. 1,2-propanediol and 1,4-dioxan (Merck, India) were used as received. 0.2 M nitric acid (Merck, India) solution was prepared. 2.0 M Sodium nitrate (Merck, India) was prepared to maintain the ionic strength in the titrand. 0.4 M Sodium hydroxide (Merck, India) was used as titrant.

The acid and base solutions were standardized by standard methods. Thus, the concentration of the alkali was determined by titrating it with standard oxalic acid and potassium hydrogen phthalate solutions, while the normality of nitric acid was determined using standardized sodium hydroxide and the primary standard borax solutions. In assessing the errors that might have crept into the determination of the concentrations, the data were subjected to analysis of variance of one way classification (ANOVA) using the computer program COST.$^{15}$ The concentration of the carbonate-free sodium hydroxide solution was determined by titrating it against nitric acid solution using the Gran plot method. ${ }^{16}$

\subsection{Alkalimetric Titrations}

The $\mathrm{pH}$ measurements of proton-ligand system were carried out in aqueous media containing varying compositions of organic solvent (propylene glycol or dioxan) in the range of $0-60 \% \mathrm{v} / \mathrm{v}$ maintaining an ionic strength of $0.16 \mathrm{M}$ with sodium nitrate at $303.0 \pm 0.1 \mathrm{~K}$ using a Digital $\mathrm{pH}$ meter MKVI type (readability 0.01 ) with mechanical stirring carried by a teflon stirrer. The $\mathrm{pH}$ metric titration assembly consisted of a double walled spoutless pyrex glass vessel of $100 \mathrm{ml}$ capacity fitted with a perspex lid through which the glass combination $\mathrm{pH}$ electrode, gas inlet-outlet tubes and burette tip were admitted. Water from a thermostat was pumped at constant rate through the annular space between the walls of the titration vessel. The titrand in the double walled spoutless pyrex glass vessel was maintained inert by bubbling dried and pure nitrogen gas throughout the course of the titration to purge carbon dioxide and oxygen. Potassium hydrogen phthalate $(0.05 \mathrm{~mol})$ and borax $(0.01$ mol) solutions were used to calibrate the $\mathrm{pH}$ meter. In each titration, the titrand consisted of approximately $1 \mathrm{mmol}$ of nitric acid in a total volume of $50 \mathrm{ml}$. The amounts of MSA in the titrands ranged between 0.25 and 0.50 mmols. The glass electrode was equilibrated in a well stirred organic solvent-water mixture containing inert electrolyte for several days. At regular intervals, the strong acid was titrated against alkali to check the complete equilibration of the glass electrode. The details of the experimental procedure and titration assembly used in our laboratory have been given elsewhere. ${ }^{17}$

\section{RESULTS AND DISCUSSION}

\subsection{Best fit Models}

The computer program $\mathrm{SCPHD}^{18}$ was used to calculate the correction factor applied to $\mathrm{pH}$ meter dial reading to calculate approximate protonation constants of mercaptosuccinic acid. The best fit chemical model for each system investigated was arrived at using non-linear least-squares computer program, MINIQUAD75 which exploits the advantage of constrained leastsquares method in the initial refinement and reliable convergence of Marquardt algorithm. ${ }^{19}$ The variation of stepwise protonation constants was analyzed mainly on electrostatic grounds on the basis of solute-solute and solute-solvent interactions.

The results of best fit models that contain the type of species and overall protonation constants of mercaptosuccinic acid along with some important statistical parameters are given in Table 1. A low standard deviation in log $\beta$ values indicates the precision of these parameters. The small values of $U_{\text {corr }}$ (the sum of the squares of deviations in concentrations of ligand and hydrogen ion at all experimental points) corrected for degrees of freedom, indicate that the experimental data can be represented by the model. Small values of mean, standard deviation and mean deviation for the system confirm that the residuals are around a zero mean with little dispersion. For an ideal normal distribution, the values of kurtosis and skewness should be three and zero, respectively. The kurtosis values in the present study indicate that the residuals form leptokurtic patterns. The values of skewness recorded in the table are between -1.88 and 1.56. These data evince that the residuals form part of a normal distribution; hence, least squares method can be applied to the present data. The sufficiency of the model is further evident from the low crystallographic $\mathrm{R}$ values. Thus, the statistical parameters show that the best fit models represent the acid-base equilibria of mercaptosuccinic acid in both PG- and DOX-water mixtures. 

M.

Table 1. Parameters of the best fit chemical models of protonation equilibria of MSA in PG- and DOX-water mixtures at $303.0 \mathrm{~K}$ and ionic strength of 0.16

\begin{tabular}{|c|c|c|c|c|c|c|c|c|c|c|}
\hline \multirow{2}{*}{$\begin{array}{l}\% \mathrm{v} / \mathrm{v} \\
\text { Organic } \\
\text { solvent }\end{array}$} & $\log \beta_{1}(\mathrm{SD})$ & $\log \beta_{2}(\mathrm{SD})$ & $\log \beta_{3}(\mathrm{SD})$ & \multirow{2}{*}{ NP } & \multirow{2}{*}{$\mathrm{U}_{\text {corr }}$} & \multirow{2}{*}{$\chi^{2}$} & \multirow{2}{*}{ Skewness } & \multirow{2}{*}{ R-factor } & \multirow{2}{*}{ Kurtosis } & \multirow{2}{*}{ pH-Range } \\
\hline & $\mathrm{LH}^{2-}$ & $\mathrm{LH}_{2}^{-}$ & $\mathrm{LH}_{3}$ & & & & & & & \\
\hline
\end{tabular}

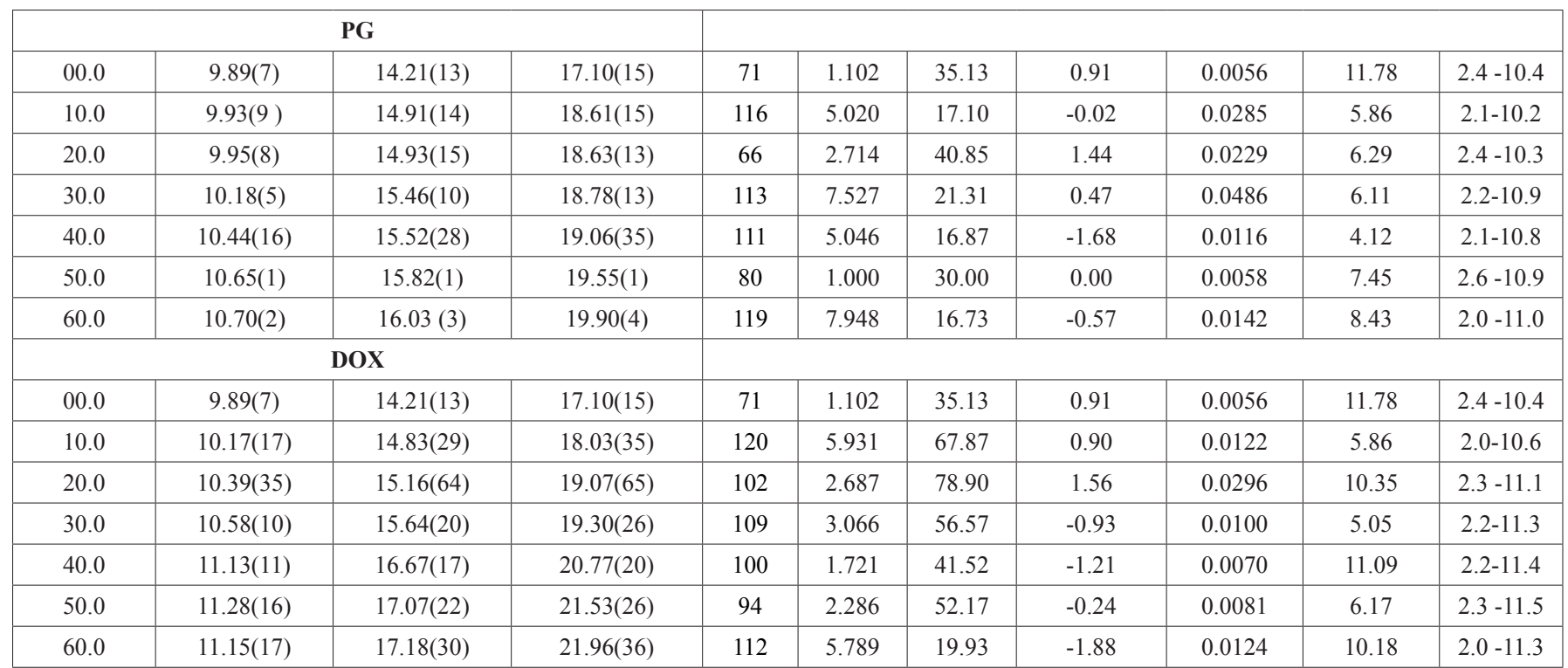

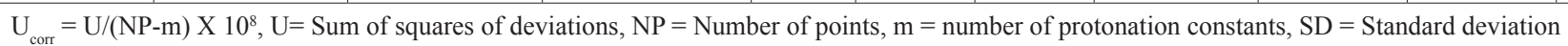

The primary alkalimetric titration data were simulated and compared with the experimental alkalimetric titration data, to verify the sufficiency of the model. The overlap of the typical experimental and simulated titrations data given in Figure 1 indicates that the proposed models correctly represent the experimental data collected from the refinements carried in the $\mathrm{pH}$ rang of 2.0 to 11.0 .
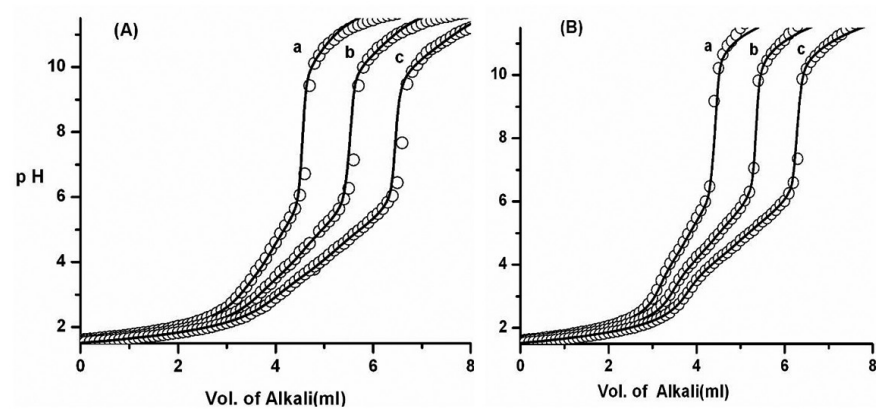

Figure 1. Simulated (o) and experimental (solid line) alkalimetric titration curves of MSA in $40 \% \mathrm{v} / \mathrm{v}$ organic solvent; (A) PG and (B) DOX: (a) 0.25 , (b) 0.375 and (c) $0.50 \mathrm{mmol}$, respectively

\subsection{Effect of systematic errors on best fit model}

Any variation in the concentrations of ingredients like alkali, mineral acid and the ligand affects the magnitudes of protonation constants. Such parameters are termed influential parameters. MINIQUAD75 does not have provision to study the effect of systematic errors in the influential parameters on the magnitude of protonation constant. In order to rely upon the best chemical model for critical evaluation and application under varied experimental conditions with different accuracies of data acquisition, an investigation was made by introducing pessimistic errors in the concentrations of mineral acid, alkali, ligand and volume. The results of a typical system given in Table 2 emphasize that the errors in the concentrations of alkali and mineral acid affect the protonation constants more than that of the ligand and volume of the solution. Increased standard deviations in the protonation constants with increased errors in the concentrations of the ingredients corroborate the appropriateness of the experimental conditions. Statistically the best chemical models that represent acid-base equilibria under study should have very low standard deviation in their protonation constant $(\log \beta)$ values that indicate the precision of the parameters. The increased standard deviation in protonation constants and even rejection of some species on the introduction of errors confirms the correctness of the proposed models. This type of investigation is significant as the data acquisition was done under varied experimental conditions with different accuracies.

\subsection{Protonation equilibria}

The step-wise protonation constants and number of equilibria can be determined from the secondary formation functions such as average number of protons bound per mole of ligand $\left(\bar{n}_{H}\right)$. The $\mathrm{pH}$ values at half integral values of $\bar{n}_{H}$ correspond to the protonation constants of the ligand and the number of half integrals in the $\mathrm{pH}$ range of the study corresponds to the number of equilibria. Thus, three half integrals $(0.5,1.5$ and 2.5$)$ in the versus $\mathrm{pH}$ curve of Figure 2 conform the presence of three protonation-deprotonation equilibria. The maximum value of in the formation curve of Figure 2 is three, which clearly shows that MSA has three bound protons per molecule.

The typical distribution plots (Figure 2) produced using the protonation constants from the best fit models given in Table I show the existence of $\mathrm{LH}_{3}$, $\mathrm{LH}_{2}^{-} \mathrm{LH}^{2-}$ and $\mathrm{L}^{3-}$ species. The $\mathrm{LH}_{3}$ species is predominant at low $\mathrm{pH}$ and its amount decreases exponentially and becomes almost zero around $\mathrm{pH} 6$, and $\mathrm{LH}_{2}^{-}$exists in the $\mathrm{pH}$ ranges 2.0-9.0. The most predominant species, $\mathrm{LH}^{2-}$ form of mercaptosuccinic acid is present to an extent of $90 \%$ starting around $\mathrm{pH}$ 3.0. The free ligand $\left(\mathrm{L}^{3-}\right)$ concentration progressively increases starting from around $\mathrm{pH} 9.0$ and attains its maximum at higher $\mathrm{pH}$ in both the media. The plotting percent of species vs. $\mathrm{pH}$ could be also used to approximate protonation constants because at the upper intersections where the points $\left[\mathrm{LH}_{\mathrm{n}}\right]=\left[\mathrm{LH}_{\mathrm{n}-1}\right]$ occurs at a $\mathrm{pH}$ values equal to the protonation constants. 


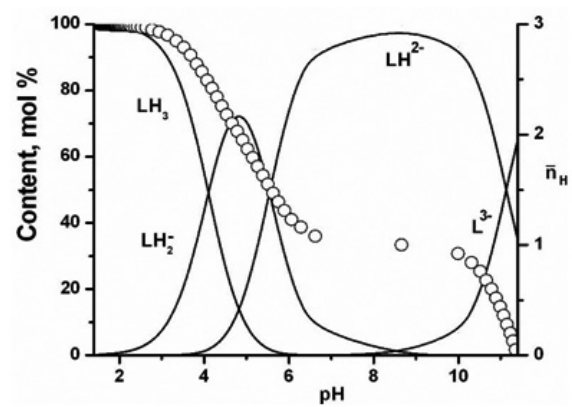

Figure 2. Formation function (o) and distribution diagrams (solid lines) of protonated and deprotonated MSA species in $40.0 \% \mathrm{v} / \mathrm{v}$ DOX-water mixture.

Table 2. Effect of errors in influential parameters on protonation constants of MSA in $40.0 \% \mathrm{v} / \mathrm{v}$ aqua-organic mixtures.

\begin{tabular}{|c|c|c|c|c|c|c|c|}
\hline \multirow{2}{*}{ Ingredient } & \multirow{2}{*}{ \% Error } & \multicolumn{3}{|c|}{ PG } & \multicolumn{3}{|c|}{ DOX } \\
\hline & & $\log \beta_{1}(\mathrm{SD})$ & $\log \beta_{2}(\mathrm{SD})$ & $\log \beta_{3}(\mathrm{SD})$ & $\log \beta_{1}(\mathrm{SD})$ & $\log \beta_{2}(\mathrm{SD})$ & $\log \beta_{3}(\mathrm{SD})$ \\
\hline & 0 & $10.45(16)$ & $15.53(28)$ & $19.07(35)$ & $11.13(11)$ & $16.67(17)$ & $20.77(21)$ \\
\hline \multirow{4}{*}{ Acid } & -5 & $10.08(34)$ & $15.87(56)$ & $18.04(71)$ & $10.87(23)$ & 16.03(39) & $19.83(50)$ \\
\hline & -2 & $10.43(20)$ & $15.50(34)$ & $19.02(42)$ & $10.99(14)$ & $16.41(22)$ & $20.40(27)$ \\
\hline & +2 & $10.58(14)$ & $15.79(24)$ & $19.46(29)$ & $11.28(19)$ & $16.94(27)$ & $21.16(32)$ \\
\hline & +5 & $10.77(21)$ & $16.20(32)$ & $20.05(36)$ & $11.56(51)$ & $17.41(64)$ & $21.78(71)$ \\
\hline \multirow{4}{*}{ Alkali } & -5 & $11.07(08)$ & $16.68(49)$ & $20.57(58)$ & $12.15(19)$ & $18.19(19)$ & $22.60(20)$ \\
\hline & -2 & $10.68(14)$ & $15.96(23)$ & $19.64(28)$ & $11.41(24)$ & $17.13(32)$ & $21.36(38)$ \\
\hline & +2 & $10.20(25)$ & $15.11(42)$ & $18.50(53)$ & $10.89(15)$ & $16.25(26)$ & $20.23(32)$ \\
\hline & +5 & $9.78(49)$ & $14.44(74)$ & $17.62(90)$ & $10.51(29)$ & $15.63(49)$ & $19.43(62)$ \\
\hline \multirow{4}{*}{ Ligand } & -5 & $10.18(24)$ & $15.11(41)$ & $18.62(50)$ & $10.88(26)$ & $16.25(26)$ & $20.35(33)$ \\
\hline & -2 & $10.36(19)$ & $15.37(32)$ & $18.90(41)$ & $11.03(13)$ & $16.50(20)$ & $20.60(24)$ \\
\hline & +2 & $10.54(14)$ & $15.69(24)$ & $19.24(31)$ & $11.23(12)$ & $16.83(18)$ & $20.94(21)$ \\
\hline & +5 & $10.68(13)$ & $15.92(22)$ & $19.49(28)$ & $11.39(18)$ & $17.08(24)$ & $21.21(28)$ \\
\hline \multirow{4}{*}{ Volume } & -5 & $10.53(16)$ & $15.53(28)$ & $19.07(35)$ & $11.12(11)$ & $16.65(17)$ & $20.76(21)$ \\
\hline & -2 & $10.45(16)$ & $15.53(28)$ & 19.07(35) & $11.13(11)$ & $16.66(18)$ & $20.77(21)$ \\
\hline & +2 & $10.45(16)$ & $15.54(28)$ & $19.07(35)$ & $11.14(12)$ & $16.67(18)$ & $20.78(21)$ \\
\hline & +5 & $10.45(17)$ & $15.54(29)$ & $19.06(36)$ & $11.15(12)$ & $16.68(18)$ & $20.78(22)$ \\
\hline
\end{tabular}

The protonation-deprotonation equilibria of MSA and $\mathrm{pH}$ ranges of existence of the species are shown in Figure 3 in which mercaptosuccinic acid loses carboxylic and thiol protons successively as the amount of alkali added increases.

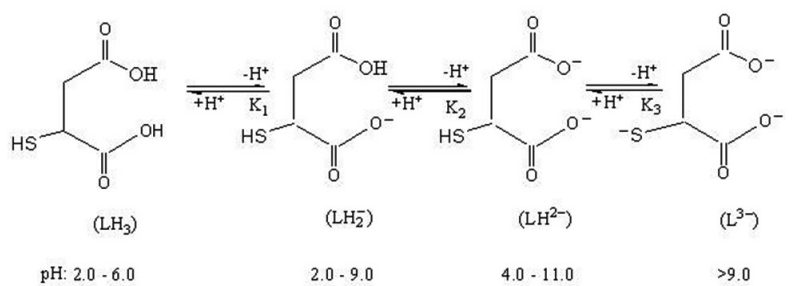

Figure 3. Protonation-deprotonation equilibria of MSA.

\section{$1.6 \quad$ Effect of Solvent}

The reaction medium is one of the most important influencing factors in determining the equilibrium constants. The solvent effect on protonation constants could be explained on the basis of dielectric constant of the medium, solvent structure, preferential solvation, and microscopic parameters..$^{20-23}$ The variation of protonation constant or change in free energy with the organic solvent content depends up on two factors: electrostatic one, which can be estimated by the Born's equation ${ }^{24}$ and non-electrostatic one, which includes specific solute-solvent interactions. When the electrostatic effects dominate the equilibrium proceeds, according to Born's equation, the energy of electrostatic interaction is related inversely to dielectric constant ${ }^{25}$ Hence, the logarithm of step-wise protonation constant $(\log K)$ should vary linearly as a function of the reciprocal of the dielectric constant $(1 / D)$ of the medium.

It is observed that in both the media the $\log K$ values of mercaptosuccinic acid increase linearly as the content of organic solvent increases. The result is in agreement with those reported in the literature for the media containing pure water as solvent ${ }^{26-29}$ but the small differences are possibly due to the different experimental procedures, temperature and different background 
electrolytes used. In this study, the linear variation of $\log K$ values as a function of 1/D (Figure 4) in both PG- and DOX- water mixtures shows the dominance of electrostatic interactions. This linear increase can be attributed to ionassociation reaction, solute-solvent interactions, proton-solvent interactions and solvent basicity (acidity) effects.

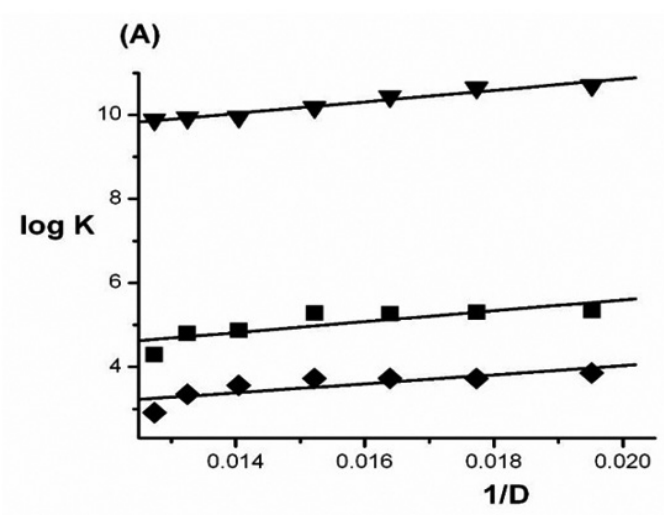

(B)

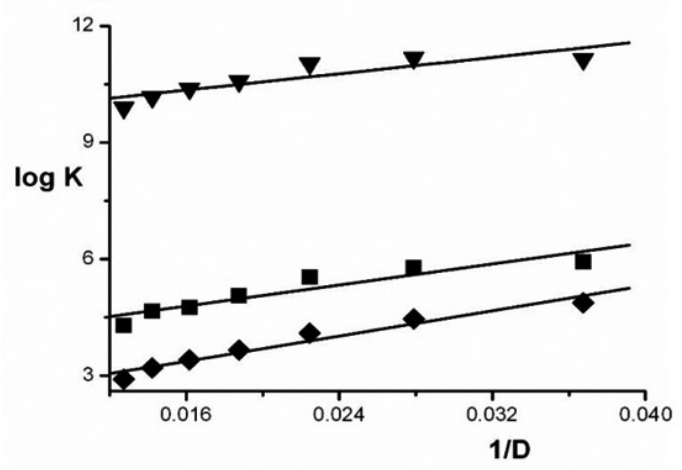

Figure 4. Variation of step-wise protonation constant ( $\log \mathrm{K})$ of MSA with reciprocal of dielectric constant (1/D) in PG-water (A) \& DOX-water mixture (B): (») $\log \mathrm{K}_{1,}(\boldsymbol{\bullet}) \log \mathrm{K}_{2}$ and ( $\left.\mathbf{\nabla}\right) \log \mathrm{K}_{3}$

\section{CONCLUSIONS}

Mercaptosuccinic acid has three dissociable protons exists in $\mathrm{LH}_{3}$ form at low $\mathrm{pH}$ and gets deprotonated with the formation of, and $\mathrm{LH}_{2}^{-}, \mathrm{LH}^{2-}$ and $\mathrm{L}^{3-}$ species, successively, with increase in $\mathrm{pH}$. The linear variation of $\log$ values of stepwise protonation constants with decreasing dielectric constant of the media confirms the dominance of electrostatic forces in the protonation-deprotonation equilibria of mercaptosuccinic acid. The effect of systematic of errors in the influential parameters on the protonation constants shows that the errors in the concentrations of alkali and mineral acid affect the protonation constants more than those in the concentration of ligand and volume of the solution.

\section{ACKNOWLEDGEMENTS}

The first author (MTZ) thanks the Federal Democratic Republic of Ethiopia Ministry of Education and Universities Capacities Building Program for financial assistance.

\section{REFERENCES}

1. S. Patai, The Chemistry of the Thiol Group, Vol. 15, Wiley-Interscience, London, 1974; pp. 569.

2. M. Rajopadhye, F. D. Popp, J. Heterocyclic Chem. 24, 1637, (1987)

3. B. S. Vashi, D. S. Mehta, V. H. Shah, Indian J. Chem. 34B, 802, (1995)

4. K. Desai, A. J. Baxi, J. Indian Chem. Soc. 69, 212, (1992)

5. M. P. Dave, J. M. Patel, N. A. Langalia, K. A. Thaker, J. Indian Chem. Soc. 61, 891, (1984)

6. R. Pires, K. Burger, Tetrahedron Lett. 37, 8159, (1996)
7. K. Nomiya, H. Yokoyama, H. Nagano, M. Oda, S. Sakuma, Bull. Chem. Soc. Jpn. 68, 2875, (1995)

8. K. C. Dash, H. Schmidbaur, Metals Ions in Biological Systems, Vol. 14, H. Sigel eds. Marcel Dekker Inc., New York, USA, 1982; pp. 179

9. P. J. Sadler, Adv. Inorg. Chem. 36, 1, (1991)

10. A. Lorber, T. M. Simon, Gold Bull. 12, 149, (1979)

11. C. Witold, K. Anna, Z. Urszula, Chem. Anal. (Warsaw) 50, 397, (2005)

12. H. Rozan, M. E. Lassman, D. P. Ridge, G. W. Luther, Nature 406, 879, (2000)

13. J. Crosby, R. Stone, G.E. Lienhard, J. Am. Chem. Soc. 92, 2891, (1970)

14. M. Arroyo, R. Torres-Guzman, I. Mata, M.P. Castillon, C. Acebal, Enzyme Microb. Technol. 27, $122,(2000)$

15. R. S. Rao, G. N. Rao, Computer Applications in Chemistry, Himalaya Publishing House, Mumbai, India, 2005.

16. G. Gran, Anal. Chim. Acta 206, 111, (1988)

17. M. P. Latha, V. M. Rao, T. S. Rao, G. N. Rao, Bull. Chem. Soc. Ethiop. 21, 363, (2007)

18. G. N. Rao, Ph. D. Thesis, Andhra University, Visakhapatnam, India, 1989.

19. P. Gans, A. Sabatini, A. Vacca, Inorg. Chim. Acta 18, 237, (1976)

20. M. Jabbar, F. Gharib, Acta Chim. Slov. 57, 325, (2010)

21. J. Barbosa, D. Barron, J. L. Beltran, S. Buti, Talanta 45, 817, (1998)

22. D. Barron, S. Buti, M. Ruiz, J. Barbosa, Polyhedron 18, 3281, (1999)

23. A. Dogan, F. Goseoglu, E. Kilic, Anal. Biochem. 309,75, (2002)

24. R. G. Bates, Determination of $p H$ : Theory and Practice, J. Wiley \& Sons, Inc., New York, 1964.

25. M. Born, Z. Phys. 45, 1, (1920)

26. A. P. Arnold, A. J. Canty, Can. J. Chem. 61,1428, (1983)

27. G. R. Lenz, A. E. Martell, Inorg. Chem. 4, 378, (1965)

28. G. E. Cheney, Q. Fernando and H. Freiser, J. Phys. Chem. 63, 2055, (1959)

29. L. J. Perrin, D. D. Perrin, Aust. J. Chem. 22, 267, (1969) 